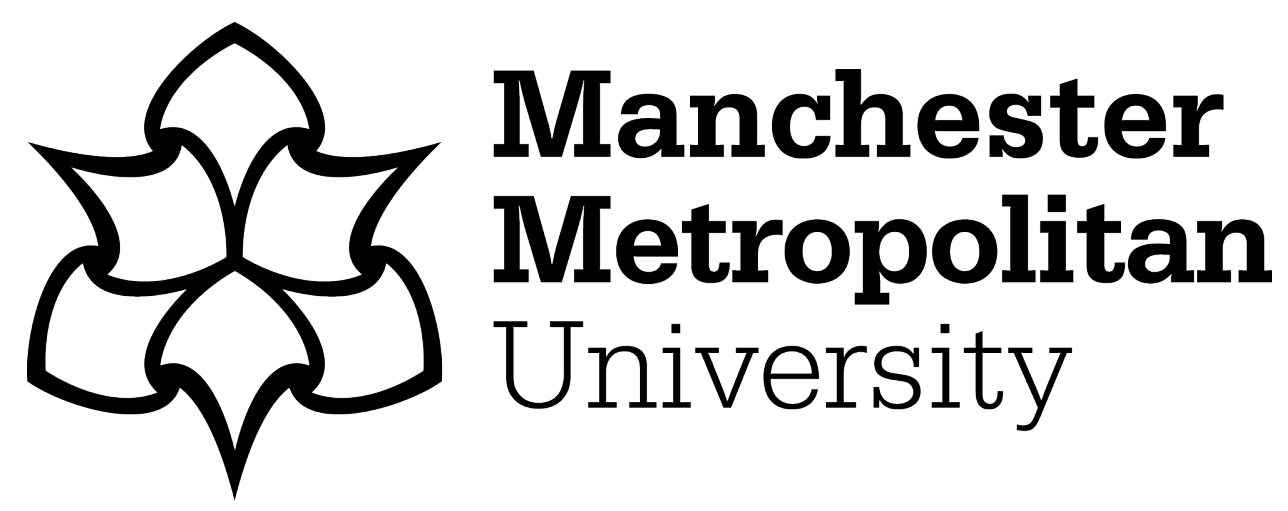

Strickland, L ORCID logoORCID: https://orcid.org/0000-0003-2560-6909 (2006) Leibniz on whether the world increases in perfection. British Journal for the History of Philosophy, 14 (1). pp. 51-68. ISSN 0960-8788

Downloaded from: https://e-space.mmu.ac.uk/344197/

Version: Accepted Version

Publisher: Taylor \& Francis (Routledge)

DOI: https://doi.org/10.1080/09608780500449149

Please cite the published version 


\section{LEIBNIZ ON WHETHER THE WORLD INCREASES IN PERFECTION}

\section{Lloyd Strickland}

In a letter to Bourguet written on 5 August 1715, a little over a year before his death, Leibniz suggests that, on the question of the world's perfection, 'Two hypotheses can be formed - one that nature is equally perfect, the other that it always increases in perfection.' (L664) ${ }^{1} \mathrm{He}$ then proceeds to split the second option into two further

\footnotetext{
${ }^{1}$ The abbreviations I use throughout when citing Leibniz are as follows: $\mathrm{A}=$ Sämtliche schriften und briefe, ed by Akademie der Wissenschaften, multiple volumes in 6 series, cited by series (reihe) and volume (band) (Berlin, 1923-). AG = Philosophical essays, trans \& ed by Roger Ariew \& Daniel Garber (Indianapolis, 1989). D = De summa rerum, trans by G. H. R. Parkinson (New Haven, 1992). $\mathrm{DM}=$ Discourse on metaphysics, cited by section number, various translations in AG, L, P, W etc. Dn $=$ The philosophical works of Leibnitz, trans \& ed George Martin Duncan (New Haven, 1908). E = Opera Philosophica, ed by J. E. Erdmann (Berlin, 1840). G = Die philosophiscen Schriften von Gottfried Wilhelm Leibniz, ed by C. I. Gerhardt, 7 vols (Berlin, 1875-1890). GM = G. W. Leibniz: Mathematische Schriften, ed by C. I. Gerhardt, 7 vols (Berlin, 1962). Gr = Textes inédits, ed by Gaston Grua, 2 vols with successive pagination (Paris, 1948). H = Theodicy, trans by E. M. Huggard (Chicago, 1990). $\mathrm{L}=$ Philosophical papers and letters, trans \& ed Leroy E. Loemker (Dordrecht, 2ed 1969). Mon $=$ Monadology, cited by section number, various translations in AG, L, P, W etc. NE $=$ New essays concerning human understanding, trans \& ed by Peter Remnant \& Jonathan Bennett (Cambridge, 1996). $\mathrm{P}=$ Philosophical writings, trans \& ed G. H. R. Parkinson (London, 1973). Pr = Protogaea, ed by Jean-Marie Barrande (Toulouse, 1993). S = Monadology and other philosophical essays, trans \& ed by Paul Schrecker \& Anne Martin Schrecker, (Indianapolis, 1965). W = Leibniz Selections, trans \& ed by P. Wiener (New York, 1951). I have generally used an English translation where available. Where no English translation is available the translation is my own. My translations have greatly benefited from the advice of Patrick Sherry, John Thorley and Elizabeth Vinestock.
} 
hypotheses, first that the world has been increasing in perfection since its inception at a first moment, and second that it has been increasing in perfection from all eternity. He illustrates these alternatives by means of the following diagrams:
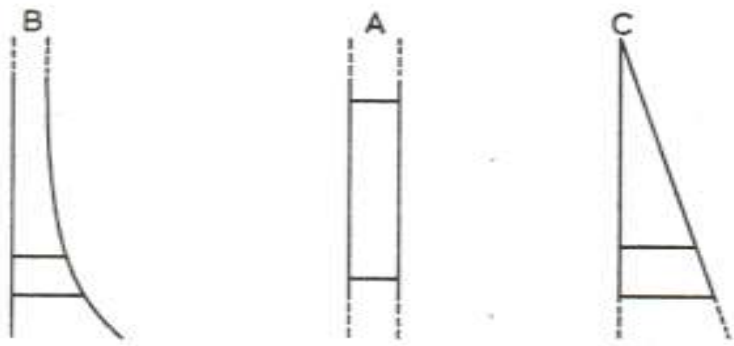

Here, rectangle A corresponds to the hypothesis that the world remains equally perfect at all moments of its (eternal) existence, hyperbola B to the hypothesis that the world has been increasing in perfection from eternity, and triangle $\mathrm{C}$ to the hypothesis that the world had a beginning and has increased in perfection since then.

Before we attempt to ascertain which of the three hypotheses gets Leibniz' support, we need to be clear about what we mean by the term 'perfection'. Leibniz identifies three varieties of perfection in all, viz. the metaphysical, physical and moral. It is notable that whenever he talks of perfection without specifying any particular kind, he almost always means metaphysical perfection, and this can be seen by looking at the many places where he attempts to define the notion of perfection (e.g. D99, D97, D45, Gr324, Gr529, DM §1 etc.). The other two kinds of perfection are usually either referred to in full as physical perfection and moral perfection, or more frequently by the words pleasure and happiness for the former, and virtue for the 
latter. $^{2}$ So for Leibniz, the question of whether the world increases in perfection is likely to be a question of whether the world increases in terms of metaphysical perfection. We shall therefore consider the question in this way, and accordingly all references to perfection should henceforth be understood as referring to metaphysical perfection.

What, though, is metaphysical perfection? Leibniz defines it as a form, quality or attribute that is 'positive and absolute in essence' (i.e. it expresses what it expresses without limit) (Gr324). This rather abstract characterisation appears to offer no clues as to which forms, qualities or attributes qualify as perfections, but Leibniz believes it is sufficient for him to pick out several clear examples:

We must also know what is meant by a perfection. A fairly sure test of it is this one: those forms or natures which are incapable of a highest degree are not perfections; for example the nature of number or figure. For the greatest number of all, or the number of all numbers, and the greatest of all figures are concepts which imply contradiction, but the greatest knowledge and omnipotence involve no impossibility $(\mathrm{DM} \S 1)$

In fact Leibniz usually identifies three, not two, separate qualities that together, in their ultimate form, constitute the perfections, and these are omnipotence, omniscience and omnibenevolence (or perfect goodness); that is to say, of course, that he identifies perfections with the attributes of God (cf. H127, H217, L639, Mon §48). The perfections of created things are taken to reside in the extent to which they

\footnotetext{
${ }^{2}$ Strictly speaking Leibniz takes physical perfection to consist in pleasure, while happiness is just an enduring state of pleasure.
} 
measure up to God, that is, by the degrees of power, knowledge and goodness that they contain (cf. H51). So the degree of perfection for any created thing at any given moment is a function of how powerful, wise and good it is at that moment (and by 'created thing' I mean a substance, soul, creature or monad, terms which I shall treat as interchangeable throughout this paper).

This gives us a measure of the degree of perfection for an individual substance, but what of the world? I would concur with George Gale's analysis that the total perfection of the world at any given moment is the sum of the perfection of every substance in that world at that moment. ${ }^{3}$ From this it is easy to see that an increase in the world's perfection would manifest as it having a larger total for this sum at one time than it did at a previous time. But what, exactly, could bring this about? As I see it, there are two ways in which the perfection of the world could be increased in a Leibnizian Universe. The first is that there are more substances at time $t$ than there were at a time before $t$. The second is that there are better, i.e. more perfect substances at time $t$ than there were at a time before $t$. The first option is ruled out by Leibniz' insistence that the total number of substances remains the same over time. ${ }^{4}$ So if there is going to be an increase in the perfection of the Universe then it will have to come from the fixed number of individual substances themselves becoming more perfect over time. This also can happen in one of two ways: firstly, by some or all things increasing in perfection over time and none actually decreasing; secondly, by some substances increasing in perfection and others decreasing, where these changes always

\footnotetext{
${ }^{3}$ George Gale 'On what God chose: perfection and God's freedom', Studia Leibnitiana 8 (1976) 75.

${ }^{4}$ The reasons for this have been well documented by Donald Rutherford. See Leibniz and the rational order of nature (Cambridge, 1995) ch. 7
} 
lead overall to a net increase in perfection (i.e. the increases are consistently greater than the decreases). ${ }^{5}$

\section{The hypothesis of the rectangle}

Returning, then, to the matter at hand, that of whether Leibniz accepts or rejects the notion of a Universe increasing in perfection, we discover that immediately after laying out the competing hypotheses of the triangle, rectangle and hyperbola, Leibniz tells Bourguet that he does 'not yet see any way of demonstrating by pure reason which of these we should choose' (L664). The matter remains under discussion throughout the rest of their communication of 1715-16, though most of Leibniz' subsequent remarks are just concerned with clearing up some of Bourguet's misunderstandings. However in another of these exchanges, ${ }^{6}$ after putting Bourguet right on the question of whether the hyperbola hypothesis entails the necessary existence of the world, Leibniz reiterates his stated view that it is not that easy to decide between the three hypotheses, and it is still necessary to engage in a lot of

\footnotetext{
${ }^{5}$ It could be argued that an increase in the world's perfection could also come via a reculer pour mieux sauter, where there would be periods of time when the total perfection of the world actually decreases, and others when it increases, with the increases outweighing the decreases over the course of time. However this seems to conflict with the triangle and hyperbola hypotheses, both of which call for a smooth continuous increase in perfection without any retrograde steps.

${ }^{6}$ From an undated letter, probably written around mid-to-late March 1716. The letter in question is a reply to two of Bourguet's letters, one from 7 February 1716 and the other from 16 March 1716. In the undated reply Leibniz asks Bourguet to obtain for him some silkworm eggs. In Leibniz’ next letter, of 3 April 1716, he thanks Bourguet for having done just this, which suggests the undated letter was written mid-to-late March 1716.
} 
meditation in order to come to any conclusion.' (G III 589) We find similar doubts expressed in the Theodicy, published 5 years beforehand:

It might be therefore that the universe became even better and better, if the natures of things were such that it was not permitted to attain the best all at once. But these are problems of which it is difficult for us to judge. (H253-4)

Curiously, however, Leibniz does express a preference elsewhere, for the rectangle hypothesis in fact. In an early letter (1674) he informs a correspondent that, 'whatever has happened, is happening, or will happen is best' (L147). Now by applying the term 'best' to the past, present and future, Leibniz is saying more than that the series as a whole is best, taken over its entire history. In fact he is suggesting that the universe is as perfect as it can be at every moment of its being, and passes from one moment to the next under the burden of being unimprovable. For clearly 'whatever has happened' would not be best on either of the two progressionist hypotheses (the triangle and the hyperbola), as on those models the world increases in perfection over time, each state of the Universe being better than the previous one. Thus Leibniz' statement about things having always been the best would sit uneasily with either the triangle and hyperbola hypotheses, and must be considered as approval for what he would later call the rectangle hypothesis.

There is further evidence for this view. In a short, previously untranslated paper entitled An mundus perfectione crescat (Whether the world increases in perfection), dated by Gaston Grua to c.1694-96, his opening words are these: 
The question is whether the whole world increases or decreases in perfection, or whether in fact it always preserves the same perfection, as I rather think, even if the different parts variously exchange perfection between themselves, so that it is mutually transferred. (Gr95)

The words 'as I rather think', while not exactly a ringing endorsement of the hypothesis of the rectangle, nevertheless suggest that, even during his mature period, Leibniz viewed the hypothesis favourably. ${ }^{7}$ Despite the recent resurgence of interest in his theodicy, this paper seems to have gone largely unnoticed by Leibniz scholars, ${ }^{8}$ and consequently also the fact that he leans towards the rectangle hypothesis in it.

On the basis of the passages considered thus far we might tentatively argue that Leibniz favoured a statically perfect world for at least some of his mature period before becoming uncertain by around 1710 at the latest.

\section{$\underline{\text { Evolution }}$}

A wholly different view has been put forward by Arthur Lovejoy. He accepts that there are grounds for thinking Leibniz 'adhered to the conception of a static universe'

\footnotetext{
${ }^{7}$ In the Theodicy Leibniz does say that 'One cannot even wish that things may go better, when one understands them' (H199) though this remark seems intended to apply to the series as a whole, and therefore probably does not count as evidence for his favouring the rectangle hypothesis in that work.

${ }^{8}$ E.g. Donald Rutherford, in his excellent examination of Leibniz' theodicy Leibniz and the rational order of nature (Cambridge, 1995), does not mention it at all. And Andrew Carlson, in his The divine ethic of creation in Leibniz (New York, 2001), does not quote from anything found in either of Grua's 2 volumes.
} 
but argues that 'the evidence is, on the whole, against it." ${ }^{9}$ In his seminal work The Great Chain Of Being he argues that Leibniz' vision of the Universe was one of 'endless Becoming', and pins this belief to some extent on the picture of Leibniz as someone who accepted the occurrence of 'phylogenetic advance', that is, the transformation, the evolution, of species. ${ }^{10}$ For example, in the Protogaea (1690-91), according to Lovejoy, Leibniz tells us that, it is 'worthy of belief that in the course of the vast changes [which have taken place in the condition of the earth's crust] even the species of animals have many times been transformed.' ${ }^{11}$ I say 'according to Lovejoy' here as it is highly doubtful that Leibniz does endorse a transformationist account in the Protogaea. For instance, in $\S 6$ Leibniz draws back from an outright endorsement of at least one evolutionary hypothesis, cautioning against the view that animals were once all aquatic before becoming amphibious and moving on to the Earth, because it 'disagrees with the writers of the Holy Scriptures, to depart from whom is a religious offence' $(\operatorname{Pr} 26)$. And in $§ 26$, from which Lovejoy's quote comes, Leibniz considers the question of why there seem to be so many 'species in stones' which cannot now be found anywhere, and answers that they probably are still around. He takes the example of a kind of large ammonite that had been found in fossils yet apparently is no longer present in the sea. He then asks the rhetorical question, 'But who has fully explored its hidden recesses, or the subterranean abysses?' (Pr90) before going on to explain that fossils are swept up by floods from

\footnotetext{
${ }^{9}$ Arthur O Lovejoy The Great Chain Of Being (Cambridge, Massachusetts, 1964) 255-6. Lovejoy does not mention or quote from Whether the world increases in perfection and was presumably unaware of it, as it was published in a volume by Grua more than decade after Lovejoy ascribed a philosophy of amelioration to Leibniz.

${ }^{10}$ Lovejoy op cit 259.

${ }^{11}$ Lovejoy op cit 256, from Pr 90.
} 
distant places, which accounts for why they are found in places where there are no living animals of the same species. Likewise the 'whirlpools of the sea' account for why some fossils seem to collect only in one place, 'such as in Malta alone we wonder at the huge number of shark's teeth which we call glossopetrae,' while even now storms 'throw up kinds of molluses onto our coasts which fishermen do not find in the nearby sea.' (Pr92) Leibniz thus envisions a variety of natural processes to explain why one can look in vain for living members of species that have been found in fossils, and why one may not find fossil records of species that are common today. All of which suggests that that when Lovejoy imputes to Leibniz the view that "many species of organisms which existed in earlier periods of geological time have now become extinct and that many known to us were then apparently non-existent,' he does so erroneously. ${ }^{12}$

But what of the passage cited by Lovejoy that we considered above, where Leibniz appears to view transformation among species as 'worthy of belief'? This can be attributed to another error on Lovejoy's part, as the passage is more accurately translated as, 'It is quite credible that during those great changes the species of animals have still remained mostly unchanged.' (Pr90) ${ }^{13}$ Lovejoy appears to have been confused by the Latin word 'immutatus' which can mean 'changed' or 'unchanged', but had he taken account of the context in which the word appears he would have been drawn to the correct translation of the term, as in the Protogaea Leibniz is clearly unimpressed by the evolutionist argument.

\footnotetext{
${ }^{12}$ Lovejoy op cit 256.

13 The Latin is 'Et credibile est per magnas illas conversiones etiam animalium species plurimum immutatas.' (Pr89)
} 
Despite this, there certainly does seem to be evidence that in his later writings Leibniz advocates at least a limited form of evolution among creatures. For example, in a letter to Thomas Burnett of 1696, he explains that, 'species can be greatly changed by the length of time, as by the interval of places, witness the differences between the animals of America and those of our region.' (G III 184) ${ }^{14}$ While this seems pretty clear-cut, I believe we should reserve judgement on it until we have considered what Lovejoy takes to be perhaps the best evidence for Leibniz' endorsement of evolutionism, which is to be found in the New Essays Concerning Human Understanding (1704). Leibniz writes there that

\begin{abstract}
Various cat-like animals, such as the lion, the tiger and the lynx, may once have been of the same race and may now amount to new subdivisions of the ancient cat species (NE317)
\end{abstract}

This remark appears during a discussion about the mixing and crossbreeding of species to produce viable offspring that are different from both parents. While Leibniz acknowledges the existence of these hybrids, his preference is to place them within the current range of species (as a subdivision) rather than considering them to belong to a wholly new and previously unactualised species. This approach is adopted again when Leibniz switches his attention from cats to dogs:

There are such great differences amongst dogs that mastiffs and lap-dogs can very well be said to be of different species. Yet it is not impossible that they are the remote descendants of the same or similar breeds, which we would find if

\footnotetext{
${ }^{14}$ Lovejoy overlooks this particular reference.
} 
we could go back a long way, and that their ancestors were similar or the same, but that after much change some of their descendants became very large and others very small (NE325)

He then proceeds to throw doubt on the suggestion that different breeds belong to different species, as 'it would not be offending against reason to believe that they have in common an unchanging specific inner nature which is not further subdivided in our world' and 'which is further varied only by the addition of accidents.' (NE325) Here Leibniz relies on the notion of a natural species, that is, a species fixed by God. If all species are natural in this sense, as Leibniz seems to imply, then there is a species called cat, another called dog, etc., and each is defined by an unchangeable inner nature that all individual members must possess no matter what their accidental properties might be. ${ }^{15}$ Leibniz extends the argument to show that "Negroes, Chinese and American Indians" likewise do not belong to different species in spite of their obvious outward differences, but are all in fact human on the grounds that they all possess reason, which he takes to be the defining feature of the human species (NE326). He then observes that

as we find among us no fixed inner feature which generates a subdivision, we have no grounds for thinking that the truth about their inner natures implies that there is any essential specific difference among men. (NE326)

\footnotetext{
${ }^{15}$ Leibniz does say that we cannot be sure if the natural species fixed by God correspond with the division of species biologists make in their tables of classification, so consequently the question of whether the word cat, for instance, denotes a true species in its own right, is open to conjecture. Nevertheless we know species boundaries to be fixed because God takes care 'to ensure that the species should be immortal' (H414).
} 
Leibniz would thus no doubt agree with Aristotle's dictum that 'man generates man, ${ }^{16}$ though he would allow that within species boundaries there can be vast differences between individuals, even differences that accumulate over time (and in many cases because of human intervention) to produce animals with different accidental properties to those that have come before (this, I think, is what Leibniz is getting at in his communication with Burnett cited above as the remarks are prompted by the discover of an 'elephant-like' fossil).

Lovejoy appears to ignore all this and argues that, so far as Leibniz was concerned, in earlier ages 'the number of [natural] species was obviously vastly reduced [from what it is today], and the descent of most forms commonly regarded as of different species from common ancestors differing very greatly from most of their descendants is implied. ${ }^{17}$ But as we have seen, that is not implied at all: the individuals representing a species might change over time to form sub-varieties, but species themselves do not change. Thus it is important to note that Leibniz nowhere suggests that the number of species around today is greater than the number of species existing in the past. In fact he advocates the very opposite view in a letter to Wagner from 1710: 'a soul or an animal before birth or after death differs from a soul or an animal living the present life only by conditions of things and degrees of perfections, but not by entire genus of being.' (W506) To fully understand this we must refer to Leibniz' acceptance of the then-vogue theory of preformationism. Following Leeuwenhoek, Leibniz held that all animals (men included) that were to develop throughout the

\footnotetext{
${ }^{16}$ Aristotle De partibus animalium 2.1 646a35, Metaphysics 7.7 1032a25, from The complete works of Aristotle, trans \& ed by Jonathan Barnes (New Jersey 1984).

${ }^{17}$ Lovejoy op cit 366.
} 
course of the universe began as spermatic animalcules, that is, miniature versions of the animals they were to become, that were present in the semen of all previous generations of animals. It is, he states, 'doubtful that an entirely new animal is ever produced but that living animals as well as plants exist in miniature in the seeds before conception' (L589). Moreover, Leibniz holds that animals never truly die, in the sense that they are wholly extinguished. Hence 'an animal ... will not end naturally; thus death... will be nothing other than an involution and diminution of the animal, when it returns from the state of a large animal to the state of an animalcule'. (E464) So what he tells Wagner is that before birth, a creature in an animalcule state already belongs to a particular species, and it remains a member of that species even after it dies (or falls into slumber, as Leibniz often puts it). With the total number of creatures fixed for all eternity it follows that the total number of species will be too, and there is thus no scope for any increase in the number of the latter nor, consequently, for phylogenetic advance.

Even if the number of species does not change, perhaps the fact that Leibniz allows there to be new hybrids, cross-breeds and sub-varieties within species is sufficient to support Lovejoy's claim that the Leibnizian Universe is ameliorative? Before we assess whether this is so, it is worth getting clear what we mean by 'new' here. After all, we must remember that there were lap-dogs, for instance, in an animalcule state long before the first lap-dog was ever born, their seeds being contained in the bodies of creatures belonging to a different sub-species (but same species). Technically, then, the sub-species of lapdog has always been present in the physical Universe, even before the first member of that sub-species achieved 'large animal' state in the world. Therefore when Leibniz talks of the sub-species of lapdog being new, what he is referring to is the moment when the first lapdog animalcule developed into a 'large 
animal', that sub-species being new only to the physical world of our day-to-day experience and not the physical world per se. Thus Lovejoy can only paint Leibniz as a progressionist if intra-species change, understood in the way described above, gives rise to more perfect 'large animals'. But nowhere does Leibniz say that the process of intra-species change makes the world better, or more perfect, or that new breeds/subvarieties are better than those already in existence (or those that have perhaps died out). While Lovejoy needs Leibniz to claim that his restricted version of evolution leads to there being either more things or better things, Leibniz in his stubbornness claims only that it leads to different things.

But might it not perhaps be argued that there is a presumption of improvement here? That intra-species change, even understood as the limited doctrine I have presented above, gives tacit support to either the triangle or hyperbola hypotheses? Such an assertion would be unwarranted. In fact, when discussing the rectangle hypothesis with Bourguet, Leibniz argues that if the hypothesis is true then 'change is appropriate, in order that there should be more kinds or forms of perfection, even if they are equal in degree.' (G III 593) Lovejoy employs this passage to bolster his own case, thereby ignoring the context in which it arises, which is only to illustrate the point that change is consistent with, and perhaps even required by the hypothesis of the rectangle. ${ }^{18}$ Leibniz makes a similar point in the Theodicy, when he considers the suggestion that the best possible world would be an eternal substance that could not

\footnotetext{
${ }^{18}$ In fact Lovejoy assumes the passage is saying that there should be more 'species or forms of perfection,' but the word 'espèce' was typically used by Leibniz to means 'kind' or 'sort', and it would only be defensible to translate it as meaning a biological species if the context was squarely biological or zoological, which is not the case here.
} 
change. There his reply is this: 'the best may be changed into another which neither yields to it nor surpasses it' (H253). The point is illustrated by the transition from

enjoyment of music to enjoyment of painting, or vice versa from the pleasure of the eyes to that of the ears, [where] the degree of enjoyment may remain the same, the latter gaining no advantage over the former save that of novelty (H253)

To Bourguet he makes the exactly the same point: that on the hypothesis of the rectangle, 'Although the Universe will always be equally perfect, it will never be sovereignly perfect, for it always changes and gains new perfections, although it loses some old ones' (G III 589). So while change has occurred, there is no reason to assume that the Universe has become any better on account of it.

\section{$\underline{\text { Progress }}$}

Lovejoy's bolt is not yet shot, however, and he claims that there is solid evidence for Leibnizian progressionism in a letter written to the Electress Sophie in November 1696, where it is stated that rational souls 'advance and ripen continually, like the world itself, of which they are images' (G VII 593) ${ }^{19}$ The letter continues to say that, 'because there is nothing outside the universe which could prevent it, it must be that the universe continually advances and develops' (ibid). And a little further on, Leibniz informs his correspondent that, 'it is a certain truth that every substance must attain all the perfection of which it is capable, and that is already found within it, enveloped as

\footnotetext{
${ }^{19}$ Lovejoy quotes from Klopp, Werke VIII 15-16, but the letter being quoted is nowadays more readily available in Gerhardt which is why I have given a reference to that.
} 
it were' (ibid). ${ }^{20}$ Lovejoy suggests that this 'attainment of all the perfection of which a substance is capable' is cumulative, i.e. that as time goes on more and more substances will reach their capacity for perfection. If that is right then Leibniz surely did believe in a world increasing in perfection, for the perfection of the world is merely the sum of the perfection of its parts, and if its parts become more and more perfect then the world too becomes more and more perfect.

Again, however, we find that when these passages are considered in their proper context they do not lend as much support to Lovejoy's hypothesis as they do when presented as standalone bite-sized quotes. Leibniz' principal aim in this letter to Sophie is to present his various ideas about the soul - that all substances are souls, that they are 'just as durable as the world itself', and consequently are 'exempt from death.' (G VII 592-93) We already know, from a passage cited previously, that 'a soul or an animal before birth or after death differs from a soul or an animal living the present life only by conditions of things and degrees of perfections, but not by entire genus of being' (W506). So while souls may indeed attain all the perfection of which they are capable, this ought to be understood as something that happens for a very short time only, when they are at their peak during this life. ${ }^{21}$ And when this life ends, although souls do not technically die in the sense that they are obliterated, nevertheless they will lose some or perhaps even most of the perfection they had during their normal life. Thus all souls undergo an increase and decrease in perfection respectively, and an overall increase in the world's perfection can only arise if the

\footnotetext{
${ }^{20}$ Lovejoy translates the latter part of this sentence as 'and which is already found in it, though in an undeveloped form'. The French is 'et qui se trouve déja dans elle comme enveloppée.'

${ }^{21}$ This is confirmed elsewhere, as Leibniz explains that a soul 'is unable to develop all at once all the things that are folded within it.' (Mon §61)
} 
individual increases are consistently greater than the individual decreases. But Leibniz does not say that this happens.

Of course he does talk of a soul ripening. But here he is doing nothing more than expounding his doctrine of universal expression. This doctrine holds that the relationship of any given soul to another is one of representation or expression; that is, every soul represents or expresses every other soul, and all souls are perpetual mirrors of the whole Universe. As he explains it to the Electress Sophie in the very same letter of November 1696 that we have been considering:

every soul...has to be as durable as the world itself, of which it is the perpetual mirror. Those mirrors are themselves universal, and every soul is an exact representation of the universe in its entirety. (G VII 592)

Thus when soul $A$ changes, the internal states of every other soul change too, because they express or mirror this change in $A$. The point Leibniz is trying to get across to the Electress Sophie is that even after a soul falls into slumber, it remains active inasmuch as it continues to represent the Universe and every change experienced by every other soul throughout the entire Universe. It is said to be active because these representative states are not caused by anything external to it, but are enclosed or enveloped within it and are unfolded over time by the soul's own power. The ripening of a soul is thus no more than a poetic way of referring to this process of continual expression of the Universe for as long as both soul and Universe persist.

Likewise, his remark in the same letter that the Universe 'continually advances and develops' because there is nothing outside it which could prevent it from doing so, says little more than that the Universe itself - taken as the sum of all substances and 
their expressions - continues to unfold, accumulating changes as it does so. If this interpretation seems a little implausible, note that Leibniz proceeds to illustrate his claim that the Universe 'continually advances or develops' by way of the following astronomical analogy:

The movement of the planets appears to be a confused matter to us who are on the globe of the earth. It seems that these stars are wandering and that they move without any rule, that they sometimes move forwards, and that afterwards they move backwards, and even that they stand still from time to time. But when we placed ourselves, with Copernicus, in the sun, at least with the eyes of the mind, we have discovered a wonderful order. (G VII 593)

Leibniz' choice of analogy here is telling, as the planets can be said to advance only in the sense that they continually follow their ordered course. But this kind of advancement or development must be understood in a very neutral way, rather like the way the advance of time or the development of a story is understood, i.e. as a progress from state to state. For progress to be made it is irrelevant whether succeeding states are better, worse or equal in value to preceding states. And just as the planets are only seen to continually advance when viewed from the right perspective, so also with individual souls or the Universe as a whole - their advancement or progress can only be appreciated if they are seen, or rather understood, in the right way, i.e. through the tenets of Leibniz' philosophy, which reveals there to be continual advancement despite appearances to the contrary. Thus even when souls seem to 'stand still' and do not undergo any changes in their degree of perfection, they nevertheless continue to 
mirror all of the ensuing changes in the Universe, and accordingly they make progress in the neutral (i.e. value-free) sense of the term.

It ought to be noted here that Leibniz usually expresses his ideas very clearly in his correspondence, particularly in his correspondence with women, and if he had meant to say to the Electress Sophie that the world was getting better, i.e. increasing in perfection, then it ought to be considered rather odd that he did not say it outright. The reason why he elected not to do so, I think, is that such a hypothesis did not correspond with his views at the time.

\section{$\underline{\text { Cultivation and development }}$}

But did it correspond to his views just one year later? Lovejoy implies as much when he suggests the 'hypothesis of continual advance' is demonstrated in a piece dating from November 1697:

A cumulative increase of the beauty and universal perfection of the works of God, a perpetual and unrestricted progress of the universe as a whole must be recognized, such that it advances to a higher state of cultivation, just as a great part of our earth is already subject to cultivation and will hereafter be so more and more ... As for the objection which may be raised, that if this is true the world will some time already have become paradise, the answer is not far to seek: even though many substances shall have attained to a great degree of perfection, there will always, on account of the infinite divisibility of the continuum, remain over in the abyss of things parts hitherto dormant, to be 
aroused and raised to a greater degree and higher condition and, so to say, to a better cultivation. And for this reason progress will never come to an end. ${ }^{22}$

How are we to square this with our tentative suggestion that Leibniz was, if anything, more favourable to the idea of a statically perfect Universe than to the hypothesis that the world increases in perfection?

Let us first consider the initial part of the first sentence. As Lovejoy reads it, it is clearly expressing the view that the Universe increases in perfection ('A cumulative increase of the beauty and universal perfection of the works of God, a perpetual and unrestricted progress of the universe as a whole must be recognized'). But given that we have already had reason to doubt Lovejoy's own translations, it might be useful to determine first of all whether this sentence is an accurate rendering of the Latin or not.

The paper from which this sentence comes is a very popular one - De rerum originatione radicali - and has appeared in many different collections of Leibniz' works, translated by many different scholars. Is there a consensus among scholars about what this sentence is actually saying? Curiously enough, no! The translations by Ariew \& Garber, Wiener and Duncan all suggest that progress is something in addition to the progress in the Universe, by which I assume they mean that progress takes place without adding to or detracting from the world's perfection, ${ }^{23}$ in

\footnotetext{
${ }^{22}$ Quoted from Lovejoy op cit 257.

${ }^{23}$ Ariew \& Garber: 'In addition to the beauties and perfections of the totality of the divine works, we must also recognize a certain constant and unbounded progress in the whole universe, so that it always proceeds to greater development.' (AG154) It should be noted that Daniel Garber, in private communication, has indicated that he is now dissatisfied with this translation.
}

Weiner: 'And in addition to the general beauty and perfection of the works of God, we must recognize a certain perpetual and very free progress of the whole universe, such that it advances always to still 
Loemker's translation it is suggested that we (men) are 'the crown of the universal beauty and perfection of the works of God', and progress in the Universe is just something we must recognise (an interpretation apparently shared by Schrecker \& Schrecker, though their translation is somewhat more obscure); ${ }^{24}$ while Parkinson's translation says that the progress of the Universe is 'towards a consummation of the universal beauty and perfection of the works of God. ${ }^{25}$

Thus in the main English editions of Leibniz' writings we find no less than three completely different renderings of the same sentence! What can we glean from all this, aside from the fact that Leibniz is often horrendously difficult to translate? My own view is that the Parkinson translation is the closest to the actual Latin of all those we have considered, though I suggest the sentence ought to be rendered as:

Furthermore, it must be recognised that there is a perpetual and most free progress of the whole universe towards a consummation of the greater improvement' (W354). This is identical to the translation in the volume by Duncan aside from Duncan ending the sentence with 'refinement' rather than 'improvement' (Dn113).

${ }^{24}$ Loemker: 'As the crown of the universal beauty and perfection of the works of God, we must also recognize that the entire universe is involved in a perpetual and most free progress, so that it is always advancing towards greater culture.' (L490-91)

Schrecker \& Schrecker: 'As the climax of the universal beauty and perfection of God's works, it must also be recognised that the total universe is engaged in a perpetual and spontaneous progress, so that it always advances towards greater culture.' (S93)

${ }^{25}$ Parkinson: 'Further, we realise that there is a perpetual and a most free progress of the whole universe towards a consummation of the universal beauty and perfection of the works of God, so that it is advancing towards a greater development' (P144) 
universal beauty and perfection of the works of God, so that it is always advancing towards greater cultivation. ${ }^{26}$

The reference to progress remains intact, but now it is clear that this progress, whatever it may consist in, consummates (i.e. is the finishing touch to) the perfection of the Universe. This is not the same thing as saying, as Lovejoy's translation does, that there is an increase in the world's perfection.

But surely, it will be argued, this is just splitting hairs? Although we know now that Leibniz is not saying outright that the world increases in perfection, he is saying that there is a progress of the whole Universe, and that this progress consummates the world's perfection. Clearly, then, the world must be increasing in perfection.

It would be wrong, I think, to construe the passage this way. For to do so is to suggest the Universe increases in perfection until it reaches the highest degree of perfection attainable. But in neither the triangle hypothesis nor the hyperbola hypothesis is it suggested that the world increases in perfection for a time and then stops because it can go no further. ${ }^{27}$ In both hypotheses perfection is considered to continue increasing for however long the Universe is in existence, and thus if the Universe does increase in perfection then it never reaches a limit.

To be sure that the progress of which Leibniz speaks is not progress in perfection, we need to explain what exactly Leibniz does mean by progress in this text. Here is the rest of the passage quoted by Lovejoy, suitably corrected:

\footnotetext{
26 'In cumulum etiam pulchritudinis perfectionisque universalis operum divinorum, progressus quidam perpetuus liberrimusque totius universi est agnoscendus, ita ut ad majorem semper cultum procedat' ( $G$ VII 308).

${ }^{27}$ It is for this reason that I think it unlikely that 'cumulum' is to be translated as 'peak', 'summit' or 'crown'.
} 
Just as now a great part of our earth has received cultivation, and will receive it more and more.... And to the objection that could be raised: that if this was so the world would already have been made paradise, my response is ready: although many substances have already come to great perfection, nevertheless because of the divisibility to infinity of the continuum, there always remain in the abyss of things parts that hitherto have been asleep, to be awakened and to be driven on to something greater and better, and as I may put it in a word, to a better state of cultivation. And hence progress never comes to an end. (G VII 308)

Interestingly, Leibniz appears here to be suggesting that progress is not the same thing as improvement! In fact it seems to be the very same neutral conception of progress that I suggested was intended in his remarks on progress to the Electress Sophie. That is, progress is merely a term to describe change over time, manifested in the continuous unfolding of what is contained in each substance. But while every substance does indeed attain the highest degree of perfection of which it is capable at any one time, we know from elsewhere in the Leibnizian corpus that they do not maintain it: death brings about a lessening of a substance's perfection.

I cannot be entirely certain that this is the point Leibniz is trying to make in $D e$ rerum originatione radicali, but even if it is not, there is another reason for considering that Leibniz is not here advocating a policy of increasing perfection. ${ }^{28} \mathrm{We}$

\footnotetext{
${ }^{28}$ Andrew Carlson opts for an entirely different interpretation of the progress referred to in De rerum originatione radicali, suggesting that it is to be understood in terms of salvation, or rather in the increase of the numbers saved over eternity; for 'over endless time ... even the worst sinners will
} 
have already seen that there are only two ways in which the Universe could be said to increase in perfection - if it contains either more things or better things at one time than at an earlier time. Leibniz, as we know, rules out the first option unequivocally, while consistently fails to advocate the second option. The fact that he fails to use obvious words such as 'better', 'improving' or 'increasing' in the above passage is very revealing in itself, as it suggests that he is again refusing to endorse the second option.

\section{The seeds of doubt}

I stated earlier the tentative view that Leibniz held the hypothesis of the rectangle to be true, at least for part of his philosophical career, after which doubts set in and he became agnostic on the matter. The question we must ask now is why this happened.

eventually be inclined to give up their hatred of God and enter onto the path of righteousness.' This strikes me as lacking in both plausibility and textual support. It is implausible because in the Confessio Philosophi Leibniz makes it clear that those whom God does not save do not then go on to achieve salvation at some later time (A VI iii 138-139); and it lacks textual support because there is nothing in the passage under discussion that implies or even vaguely suggests Leibniz is referring to salvation. See Andrew Carlson The divine ethic of creation in Leibniz (New York, 2001), 643. Another interpretation of the progress referred to in De rerum originatione radicali has been put forward by Juan A. Nicolas, who argues that, for Leibniz, 'The realisation of the best of worlds does not ... take place all at once; it is rather a matter of an historic process, with its progressions and regressions, and in which man plays an important role.' Through man's decisions and actions, Nicolas tells us, justice and happiness are made possible. If Nicolas' interpretation is right, Leibniz' talk of 'substances being awakened' must be taken figuratively rather than literally, to refer to advancements in knowledge and understanding. However it seems something of a stretch to interpret it this way. See Juan A. Nicolas 'La rationalité morale du Monde chez Leibniz' in Leibniz: Le meilleur des Mondes, ed by Albert Heinekamp \& André Robinet (Stuttgart, 1992) 168. 
I believe the roots of the answer lie in Leibniz' thoughts about physical perfection (happiness). This form of perfection, he asserts throughout his career, is subject to an unending increase over the course of time:

our happiness will never consist, and ought never to consist, in complete joy, which leaves nothing to be desired and which would stupefy our spirit, but in a perpetual progress to new pleasures and new perfections. (L641, cf. G VII 568)

Two things ought to be noted about this claim. Firstly, the start of the continuous increase is deferred to 'the future' (S125), in 'another life' (L564) after 'the books are balanced' (L218). Secondly, the perpetual increase only applies to some souls, not all. A small minority will experience ever-increasing happiness, while an unfortunate majority will become ever more unhappy (cf. A VI iii 139). It is clear from this, I think, that Leibniz is looking to the afterlife to trigger this twin escalation of happiness and unhappiness, and the event that initiates it is the administering of divine justice, where some souls are saved and elevated into God's presence for eternity while others are damned and shut out from His presence forever (and perhaps cast down to hell).

Leibniz' best of all possible worlds thus comprises two distinct stages. The first stage is the mortal world we know, where creatures are born, live and then fall into slumber. The second stage sees the simultaneous re-awakening of all sleeping creatures in order for justice to be administered, some creatures being saved and granted an eternal communion with God, others being damned and forced to eternally wallow in their own increasing misery. Leibniz clearly considers both stages to be 
part of the same world as he defines the world as 'the whole succession and the whole agglomeration of all existent things.' (H128, cf. S116)

One might wonder why all this is relevant; after all, the fact that a creature's physical perfection may increase without end in the second stage of the Universe does not seem to have any obvious link to whether its metaphysical perfection increases. But as it happens there is a link, as any increase in physical perfection can only come about through a prior increase in metaphysical perfection, as is clear from the following remark in the New Essays:

I doubt that a greatest pleasure is possible; I am inclined to believe that it can increase ad infinitum, for we do not know how far our knowledge and our organs can be developed in the course of the eternity which lies before us. So I would think that happiness is a lasting pleasure, which cannot occur without a continual progress to new pleasures (NE194)

What Leibniz reveals here is that happiness increases because of an increase in knowledge (of God, in this case), and knowledge, as we know, is one of the attributes that determines a creature's overall degree of metaphysical perfection. So the more knowledge a creature has, the happier it becomes, and if a creature's happiness increases ad infinitum, as Leibniz confirms, then this is because its metaphysical perfection is increasing ad infinitum. It thus follows, then, that blessed creatures experience a continual increase in perfection (metaphysical and physical) while the damned suffer a continual decrease in perfection. ${ }^{29}$

\footnotetext{
${ }^{29}$ Moral perfection likewise increases and decreases, as the wiser one is the more virtuous one is, and vice versa.
} 
Now we know that Leibniz believed in a statically perfect Universe for at least some of his philosophical career. We can now see that such a Universe will have to preserve a particular degree of perfection throughout both stages of its existence. That is to say, the Universe must remain as equally perfect throughout the whole of the first stage as it must throughout the whole of the second stage, for only then can it truly be said to remain equally perfect at all times. This view thus entails that, when the second stage of the Universe begins, after divine judgement has been meted out, the increases in perfection enjoyed by the blessed are equal to the decreases in perfection suffered by the damned. In An mundus perfectione crescat, Leibniz concurs with this analysis:

If the perfection of the world remains the same, some substances cannot continually increase in perfection without others continually decreasing in perfection. (Gr95)

This, then, was Leibniz' opinion during the time he believed in a statically perfect Universe. As he eventually fell into uncertainty on this matter, and decided not to categorically rule out the possibility that the Universe was ameliorative, one might expect to find in his later writings some basis for this uncertainty. Given what we now know about the two-stage Universe, and the fact that continuous increases in perfection are only possible for creatures in the second stage, Leibniz must have come to question whether the perfection of the Universe remained static in this second stage. So what we might hope to find in Leibniz' later writings is a consideration of the possibility that the Universe might increase in perfection during this second (postjudgement) stage. And in the Theodicy this is precisely what we do find: 
For it is possible, and even a very reasonable thing, that the glory and the perfection of the blessed may be incomparably greater than the misery and imperfection of the damned, and that here the excellence of the total good in the smaller number may exceed the total evil which is in the greater number. (H379)

What Leibniz is considering here is whether the increases in perfection experienced by the elect might outweigh the decreases in perfection suffered by the damned. If that does indeed occur then the world can be said to increase in perfection, at least in the second of its two distinct stages. But Leibniz only considers this to be 'possible' and 'reasonable', and he falls some way short of actually endorsing it. Nevertheless his speculation on this matter ties in with his documented uncertainty on the question of whether the world increases in perfection and explains why he became uncertain about that.

One final question remains, however. Why did he come to think that the increases in perfection of the blessed might outweigh the decreases in perfection of the damned? In an early work, the Confessio Philosophi from 1672-3, Leibniz has this to say on the matter:

the blessed...experience delight incessantly...because without perpetual novelty and progress there is no thinking and hence no pleasure...[yet] those who are furiously against the nature of things...they will be continually irritated by new objects of indignation, of hatred, of jealousy and, to say it in one word, of madness. (A VI iii 139) 
Yet almost 40 years later in the Theodicy, Leibniz was not so quick to state that the damned continually get worse, arguing instead that in their descent they would eventually reach or at least approach a lowest possible limit:

The blessed draw near to divinity through a divine Mediator, so far as can belong to these created beings, and make such progress in good as is impossible for the damned to make in evil, even though they should approach as nearly as may be the nature of demons. God is infinite, and the devil is finite; good can and does go on ad infinitum, whereas evil has its bounds. (H379)

It might seem odd that the later Leibniz was so certain that the blessed undergo an unlimited increase in perfection and the damned a limited decrease in perfection, while remaining uncertain on the question of whether the Universe as a whole increases in perfection. But it is not really odd at all, for with the fates of an infinity of creatures to take into consideration even a superlative mathematician like Leibniz was at a loss to calculate whether the infinite gains made by some creatures either balanced or outweighed the finite losses incurred by what was presumably an infinity of others. And this, I suspect, was why he informed Bourguet that he could see no way of demonstrating which one of the rectangle, triangle and hyperbola hypotheses was true. ${ }^{30} 31$

\section{Lancaster University}

\footnotetext{
${ }^{30}$ Full English translations of many of the previously-untranslated Leibniz texts cited in this paper can be found on my website at http://www.leibniz-translations.com

${ }^{31}$ My thanks to Vernon Pratt, Patrick Sherry and Chakravarthi Ram-Prasad for their comments and suggestions on an earlier draft of this paper.
} 